\title{
Conceptual Design of the CSP Lead Demonstrator SOLEAD
}

I. Di Piazza ${ }^{1, *}$, A. Tincani', R. Marinari², M. Valdiserri', S. Bassini', A. Rinaldi ${ }^{3}$, L.Turchetti ${ }^{3}$, M. Serra ${ }^{1}$, A. Antonelli', D. Delfino ${ }^{4}$

${ }^{1}$ ENEA C.R. Brasimone, Camugnano (Bo), 40032, Italy

${ }^{2} \mathrm{DICl}$ University of Pisa, Pisa, 56122, Italy

${ }^{3}$ ENEA C.R. Casaccia, Roma, 00123, Italy

${ }^{4}$ DENERG - Politecnico di Torino, 10129, Torino, Italy

*Corresponding author: E-mail: ivan.dipiazza@enea.it

DOI: $10.5185 /$ amlett.2020.061531

The NEXTOWER H2020 EU project investigates the possibility of using liquid lead as heat storage medium for high-temperature Thermal Energy Storage (TES) in concentrated solar power plants. To that end, within such project, a demonstration TES unit named SOLEAD (SOlar LEAd Demonstrator) is being developed and will be coupled with an open volumetric air receiver in a solar tower CSP system. The SOLEAD demonstrator will be built and operated at the Plataforma Solar de Almeria (Spain) as a result of the project effort.

In the present paper, the conceptual design of the SOLEAD demonstrator is illustrated in details. Basically, SOLEAD is a single-tank thermocline TES system using a pool of liquid lead as heat storage medium. The receiver collects energy from the solar field and heats atmospheric air up to $900^{\circ} \mathrm{C}$; the hot air is then used to thermally charge the SOLEAD system through an air-lead primary heat exchanger located in the lower part of the lead pool. In particular, one of the goals of the design is to reach a temperature stratification from $600^{\circ} \mathrm{C}$ (lower part) to $750^{\circ} \mathrm{C}$ (upper part), which cannot be achieved with the common molten salt mixtures used in commercial TES systems for CSP applications. The thermal stratification is obtained by positioning the primary heat exchanger in the bottom part of the pool and by exploiting the buoyancy forces to promote natural circulation in the pool. This method avoids the use of a pump with an impeller and a proper orifice calibration allows to attain in the average the required mass flow rate and temperature drop in the system. The design of the air-lead primary heat exchanger is innovative and challenging due to the poor heat transfer properties of the atmospheric air at $900^{\circ} \mathrm{C}$. The Heat exchanger is counter-current bayonet type with the air on the bayonet side and the lead on the shell side. The design of the heat exchanger was performed by a large use of CFD tools and modelling and includes a riser to guide the flow path and to bring the hot fluid in the top part of the pool.

The thermal discharge of the SOLEAD TES system is carried out through a secondary heat exchanger located in the upper part of the tank, which allows the transfer of heat from the pool to compressed air at 10 bar used as secondary heat transfer fluid. The design of the secondary heat exchanger was made by the use of CFD and the $\mathrm{HX}$ is made of U-pipes with air in the internal side.

Due to the high temperatures involved, the choice of structural materials facing the hot lead is critical for the project and was made with the strong collaboration of the industrial partners of the project. In particular, FeCrAl Alloys were largely used to face the hot lead and limit corrosion issues. FeCrAl materials are industrially used to limit corrosion in harsh environments.

The overall design of the vessel and internals was a compromise among power exchanged, desired temperature drop, materials and costs. The design process of the SOLEAD system and the engineering methodologies adopted for the project choices are described in the paper.

\section{Introduction}

Among the renewable energy technologies based on nonprogrammable sources, concentrated solar power (CSP) is the only one currently allowing for dispatchable production, thanks to the availability of commercial thermal energy storage (TES) solutions with capacities that, in the current industrial implementations, reach up to $15 \mathrm{~h}$ at full load. The currently most advanced commercial CSP plants are based on the central receiver technology and use a mixture of molten salts $\left(\mathrm{NaNO}_{3}-\mathrm{KNO}_{3}, 60 / 40\right.$ $\%$ w/w) both as heat transfer fluid (HTF) and heat storage medium. In such plants, solar heat is collected at a maximum temperature of $565^{\circ} \mathrm{C}$ and supplied to a superheated steam cycle for power production. The maximum operating temperature is limited by the thermal stability of molten salts and other material issues related to the system components from the receiver to the TES system. CSP research worldwide is currently aimed at addressing these challenges and achieve higher operating temperatures, in order to enable power productionwith more efficient cycles (e.g., supercritical $\mathrm{CO}_{2}$ cycles) [1,2].

By using atmospheric air as HTF, solar towers equipped with open volumetric receivers are able to 


\section{Advanced Materials Letters www. vbripress.com/aml}

achieve such higher temperatures: as an example, in the Juelich solar tower in Germany, an experimental plant with a capacity of $1.5 \mathrm{MW}$ (electric) in operation since 2008, air is heated up to $700^{\circ} \mathrm{C}$ [3]. Despite this potential, the commercial deployment of atmospheric air towers is still hindered by the reliability and lifetime of the receiver components and by the lack of consolidated TES solutions with high capacity and efficiency at this temperature level.

In this framework, the NEXTOWER H2020 EU project investigates new material solutions for open volumetric air receivers and the possibility of using liquid lead as heat storage medium for high-temperature Thermal Energy Storage (TES). To that end, within such project, a demonstration TES unit named SOLEAD (SOlar LEAd Demonstrator) is being developed and will be coupled with an open volumetric air receiver in a solar tower CSP system. The SOLEAD demonstrator will be built and operated at the Plataforma Solar de Almeria (Spain) as a result of the project effort.

A large experience on Heavy Liquid Metal (HLM) facilities exists at the ENEA C.R. Brasimone in Italy. The experience is related both to design and operation of such facilities and experimental results collected lead to publication in International research journals, see [4-7] as examples. At the ENEA C.R. Brasimone a large experimental facility fleet exists and it includes both loop and pool facilities. In particular, the pool facility CIRCE $[8,9]$ is the largest HLM pool facility in Europe and it is used to perform integral thermo-fluid dynamic tests in the framework of GEN-IV HLM cooled nuclear reactors research field.

An overall technological transfer is therefore carried out from the HLM technology related to the GEN-IV nuclear reactors to the solar TES demonstrator SOLEAD. In particular, the experience on air-HLM heat exchangers as well as the experience in the thermal stratification phenomena in the pool type facilities were fully used to propose and develop the SOLEAD DEMO.

The SOLEAD system builds on a TES concept developed by ENEA in previous research actions and its implementation takes advantage of the experience gained with the CIRCE facility in the ICE configuration [8]. An overall view of the technology of HLM systems can be seen in [10], while thermal-hydraulic issues related to this technology are provided in [11].

Four main systems can be identified in the SOLEAD Demo: the primary side (lead), the secondary side, the gas feeding circuits, the Filling \& Draining circuit (melting furnace, storage tank, connection pipe between tanks).

The goal to make a lead system at $800^{\circ} \mathrm{C}$ to be interfaced with concentrated solar power (CSP) air-based tower systems is ambitious. In fact, a lead system at $800^{\circ} \mathrm{C}$ was never designed before and criticalities on materials facing hot lead exist.

The development of the design of this demonstrator was carried out with continuous interactions with the NEXTOWER consortium, mainly CALEF, SANDVIK and CIEMAT/PSA, in an iterative process, where the solutions were obtained as a tradeoff accounting for functionality, manufacturability issues and compatibility of structural materials with lead at very high temperatures.

In particular, this paper reports the ENEA SOLEAD conceptual design developed in 2017 , mainly constituted by: 1) the Piping \& Instrumentation Diagram, P\&ID with the full lists of instrumentation and components and with the description of the main process of the facility, including basic operating procedures; 2) the preliminary basic design (main dimensions/solutions to adopt) for the main components as the draining/storage tank, main vessel and the primary and secondary heat exchangers; 3 ) the conceptual design of the Data Acquisition and Control system DACS, both for the acquisition and power panels.

\section{SOLEAD functionality requirements}

The implementation of the conceptual design of the demo system was performed considering the following main functional requirements for the lead facility:

1. To provide adequate heating in order to maintain lead in the liquid state in the whole system;

2. To allow to work in natural circulation with lead in the main vessel;

3. To absorb heat coming from the primary air circuit (primary HX);

4. To heat the air of the secondary air circuit (secondary HX);

5. To control oxygen content in lead through the Oxygen Control System (OCS);

6. To ensure draining by cover gas pressurization of the main vessel;

7. To accommodate possible overpressures of the liquid metal.

The main operative conditions considered for the conceptual design of SOLEAD are summarised in Table 1.

Table 1. Main operative conditions in the SOLEAD demo.

\begin{tabular}{|c|c|c|}
\hline \multicolumn{3}{|l|}{ Process Fluid Lead } \\
\hline Description & Value & Unit \\
\hline Main vessel maximum temperature & 815 & ${ }^{\circ} \mathrm{C}$ \\
\hline Main vessel maximum pressure & 0.750 & $\mathrm{MPa}$ \\
\hline Storage vessel maximum temperature & 550 & ${ }^{\circ} \mathrm{C}$ \\
\hline Storage vessel maximum pressure & 0.750 & $\mathrm{MPa}$ \\
\hline $\begin{array}{l}\text { Lead connection piping maximum temperature } \\
\text { (inside main vessel) }\end{array}$ & 815 & ${ }^{\circ} \mathrm{C}$ \\
\hline $\begin{array}{l}\text { Lead connection piping maximum temperature } \\
\text { (outside main vessel) }\end{array}$ & 550 & ${ }^{\circ} \mathrm{C}$ \\
\hline Lead connection piping maximum pressure & 0.750 & $\mathrm{MPa}$ \\
\hline \multicolumn{3}{|l|}{ Process Fluid Air } \\
\hline Description & Value & Unit \\
\hline Primary heat exchanger maximum temperature & 850 & ${ }^{\circ} \mathrm{C}$ \\
\hline Primary heat exchanger maximum pressure & 0.100 & $\mathrm{MPa}$ \\
\hline Primary heat exchanger inlet pressure & 0.085 & $\mathrm{MPa}$ \\
\hline Secondary heat exchanger maximum temperature & 750 & ${ }^{\circ} \mathrm{C}$ \\
\hline Secondary heat exchanger maximum pressure & 1.500 & $\mathrm{MPa}$ \\
\hline Secondary heat exchanger inlet pressure & 1.000 & $\mathrm{MPa}$ \\
\hline
\end{tabular}




\section{Advanced Materials Letters www. vbripress.com/aml}
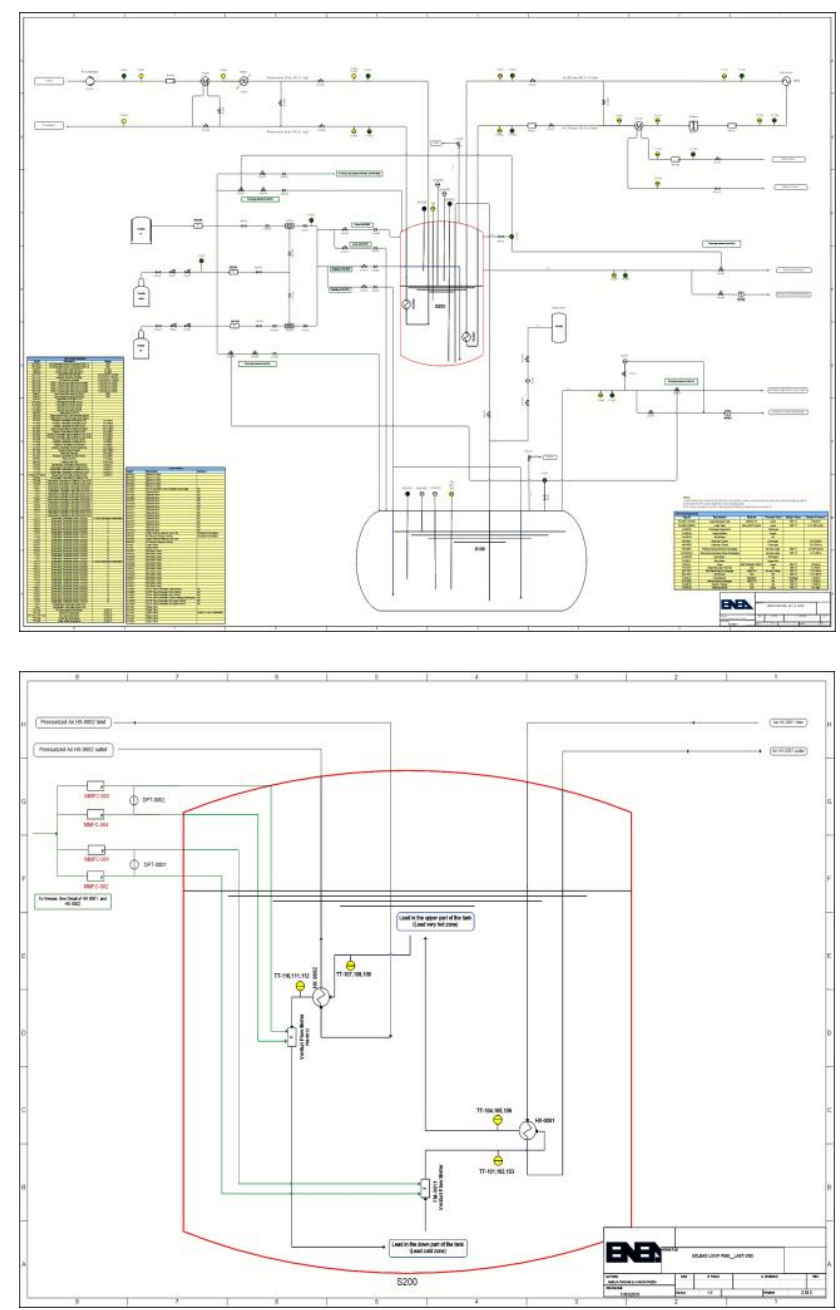

Fig. 1. P\&ID of the SOLEAD facility.

\section{SOLEAD general layout}

During the conceptual design phase, the SOELAD P\&ID was developed and optimized with the support of CALEFSRS and CIEMAT-PSA. Fig. 1 shows the P\&ID of SOLEAD also including the primary and secondary air circuits, whose conceptual design is under CIEMAT responsibility.

The SOLEAD facility is mainly composed by the following parts:

- The main vessel (S200) in which the two heat exchangers are placed;

- The two gas feeding circuits;

- The solar receiver (SB 30);

- The Filling \& Draining circuit (melting furnace, storage tank S100, and the

- connection pipe between tanks);

- The Oxygen Control System (OCS);

- Piping and valves;

- Instrumentation and heating and thermal insulation systems

Fig. 1 reports the piping and instrumentation Diagram (P\&ID) of the SOLEAD facility, while the conceptual layout of the storage tank S200 is reported in Fig. 2.

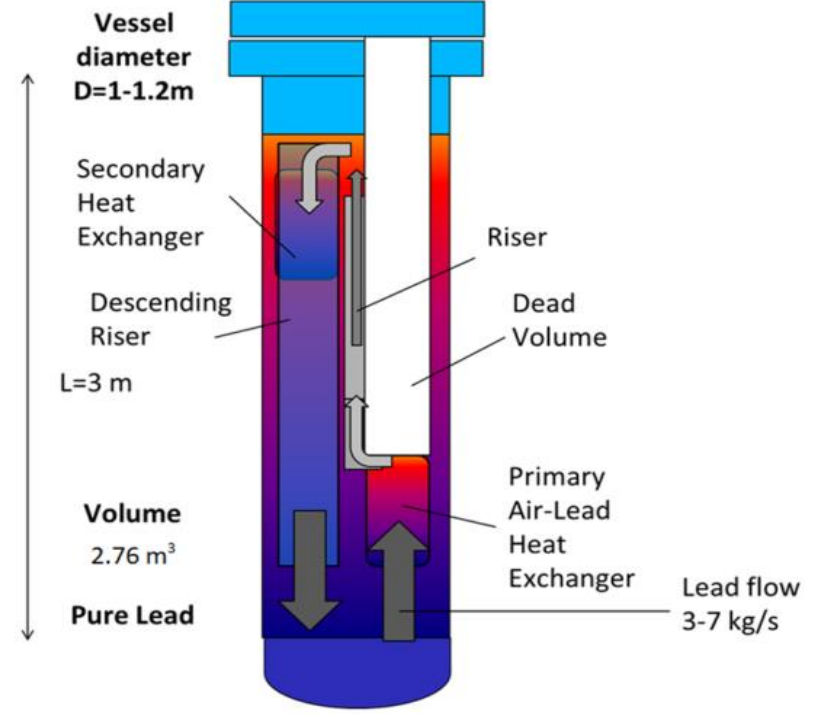

Fig. 2. Conceptual layout of the storage tank S200.

The main vessel, S200 is a tank with a vertical orientation, an elliptical bottom head and a flanged connection in the upper part. The best candidate structural material is Alloy 800 steel with an internal cladding of $\mathrm{FeCrAl}$. The tank is filled with pure lead at temperature up to $750^{\circ} \mathrm{C}$ and houses the primary (HX-0001) and secondary (HX-0002) heat exchanger devoted to the thermal charge and discharge tests, respectively. Most of the conceptual design effort was devoted to the development and design of the primary and secondary heat exchangers.

The primary heat exchanger is made by 85 tubes in tubes (bayonet concept). In the inner tubes and the annular region between inner tube and outer tube, the process fluid is air in slight depression (850 mbar) while the external fluid is liquid lead (with temperature from $600{ }^{\circ} \mathrm{C}$ up to $750{ }^{\circ} \mathrm{C}$ ). The secondary heat exchanger (lead/pressurized air) is constituted by $30 \mathrm{U}$-shaped tubes.

The difference in height between the two heat exchangers $(1.5-2.0 \mathrm{~m})$ provides the proper pressure head to work in natural circulation to simplify the management of the system. A 'dead volume' ensures that the primary HX remains in the vessel bottom part. This concept, schematically reported in Fig. 2 will ensure both lead natural circulation and thermal stratification. In similarity with CIRCE-ICE design, a hot riser is installed to drive the hot plume in the top part and allow stratification.

When the primary HX is active, the heat flow is transferred from the hot air into the lead through the primary HX and the hot lead is driven in the upper part of the vessel by the riser (thermal charging phase); this allows the formation of thermal stratification with associated energy accumulation (TES function).

This stored energy can be transferred to pressurized air in the secondary circuit by the use of the secondary HX, which removes heat from the hot lead in the upper part of the vessel and drives the resulting cold lead in the bottom part through the collector. 


\section{Advanced Materials Letters www. vbripress.com/aml}

\section{Storage Tank S100}

The storage tank, S100, is a tank with horizontal orientation, two elliptical heads and two 16 inches flanged penetrations for instrumentation, gas pipes and lead filling \&draining piping. The best candidate structural material is AISI 316 steel.

A connection pipe between the storage and the main tank is foreseen for the filling and draining operations of S200. The lead is charged from S100 to S200 increasing the pressure of S100 cover gas, while draining of S200 into S100 is performed pressurizing the S200 cover gas. In agreement with other partners of the project, the gravitational draining of the main vessel was excluded by design, in order to avoid a nozzle with critical weld under lead at high temperature in the bottom head of the main vessel. Despite this, for the lead horizontal pipe a $3 \%$ slope of inclination is still recommended.

The Oxygen Control System (OCS) is constituted by an $\mathrm{Ar}-\mathrm{H}_{2} / \mathrm{O}_{2}$ injection system in the vessels $\mathrm{S} 200, \mathrm{~S} 100$ and three oxygen sensors: one in the storage tank and two in the main vessels at two different heights. With this device, the oxygen content in the loop is kept under control and the formation of oxide debris is prevented. Oxygen is maintained in the range $10^{-6}-10^{-8} \mathrm{wt} \%$, in order to prevent lead oxide formation and to avoid dissolution attack. A reference the OCS design and operation can be found in [12].

During maintenance and idle phases, the lead can be recovered in the storage tank S100. Moreover, each vessel is equipped with a dedicated safety valve that acts in case of over-pressurization.

A full description of the main process of the facility is reported in [13]. For the lead connection pipe outside the main vessel S200, AISI 316 was selected as best candidate material; while for the pipe inside the main vessel, the Alloy $800 /$ Sanicro $31 \mathrm{H}+$ Loafer (FeCrAl alloy) will be used.

The diagnostics, instrumentations and control foreseen in SOLEAD demonstrator are:

- Mass flow meters in lead and gas phases;

- Temperature meters (thermocouples);

- Absolute and relative Pressure meters;

- Absolute pressure meter in Gas phase;

- External heating control measurement;

- Lead Level meters;

- Oxygen sensors in lead.

Where the process fluid is heavy liquid metal, both tubes and components (tanks, valves, etc.) are traced by electrical heating cables. At least three thermocouples are installed for each heating cable placed, in order to ensure the correct control of the liquid metal inside the pipe. Moreover, a dedicated system for monitoring the oxygen content in the lead has to be developed and installed.

For the storage tank, S100 after long discussions with SANDVIK/CALEF and a comparative analysis among the different steels used, AISI316, for which a large ENEA experience exists at the design temperature of $550{ }^{\circ} \mathrm{C}$, was fixed as structural material. The conceptual design of the heating and thermal insulation system of the storage tank and the other components was also carried out with a maximum acceptable outer surface temperature of insulation of $50{ }^{\circ} \mathrm{C}$.

\section{Main Vessel S200}

The main vessel, S200, showed in Fig. 3, devoted to host the two heat exchangers, was designed with a vertical orientation, an elliptical bottom head and a flanged connection in the upper part. The basic dimensions of the vessel are an inner diameter of $1160 \mathrm{~mm}$, and a height of $3.6 \mathrm{~m}$.

After long discussions with SANDVIK/CALEF and a comparative analysis among the different steels used for application at high temperatures, the following solution was found: ALLOY 800 (Sanicro $31 \mathrm{HT}$ ) and an overlay welding/liner (SANDVIK/CALEF feedback) of FeCrAl as functional material to avoid corrosion were selected. The structural material has a very good performance at high temperatures and allows to reduce the thickness of S200 to $32 \mathrm{~mm}$ (compared to the austenitic steel 253MA). The drawback is that, in case of overlay welding failure, the steel can be highly corroded by the hot lead (Ni dissolution) with respect to an austenitic steel.

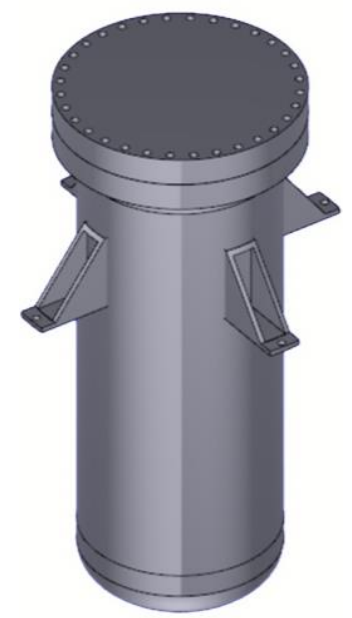

Fig. 3. D rendering of the SOLEAD main vessel S200.

\section{Primary Heat Exchanger}

The aim of the primary heat exchanger is to work as heat source in the lower part of the main vessel, to trigger the natural circulation and recover the heat flow coming from Solar Receiver. Most of the design effort was devoted to the correct sizing and design of this component.

The primary heat exchanger is constituted by 85 tubes in tubes (bayonet concept), see Fig. 4. In the inner tubes and the annular region between inner tube and outer tube the process fluid is air under sight vacuum $(850 \mathrm{mbar})$ while the external fluid is liquid lead (with temperature from $600{ }^{\circ} \mathrm{C}$ up to $750{ }^{\circ} \mathrm{C}$ ). The air enters through the annular gap and then goes up through the central pipe of the bayonet. 


\section{Advanced Materials Letters www. vbripress.com/aml}

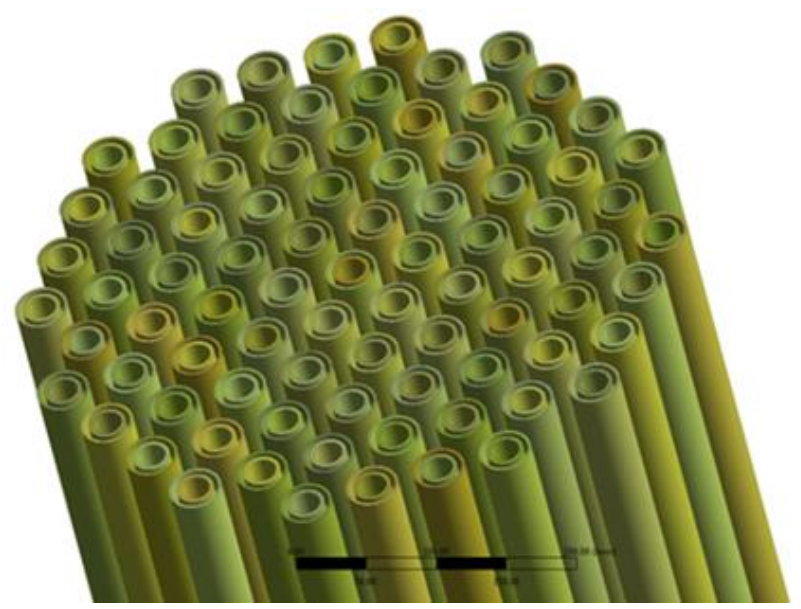

Fig. 4. HX-001 bundle of 85 tubes.

The primary heat exchanger (lead/depressurized air) was developed and analysed by a large use of Computational Fluid Dynamics (CFD) and System Thermal Hydraulics code (RELAP5) for design. By a CFD model of a single tube a basic design was made. Then a Relap model of the whole heat exchanger was carried out. Particular attention was focused on the design of the air inlet/outlet collectors.

The external bayonet pipe was fixed according to the commercial availability of pipes from Sandvik. Then, with a fixed active length of about $1 \mathrm{~m}$, the CFD model of a single tube was run to establish the power exchanged at the design lead flow rate that guarantees a temperature drop of $150^{\circ} \mathrm{C}$ (from $600^{\circ} \mathrm{C}$ to $750^{\circ} \mathrm{C}$ ); see Fig. 5 for an example of temperature distribution in a section of the pipe. Finally the number of pipes was fixed to reach the overall power of $100 \mathrm{~kW}$.
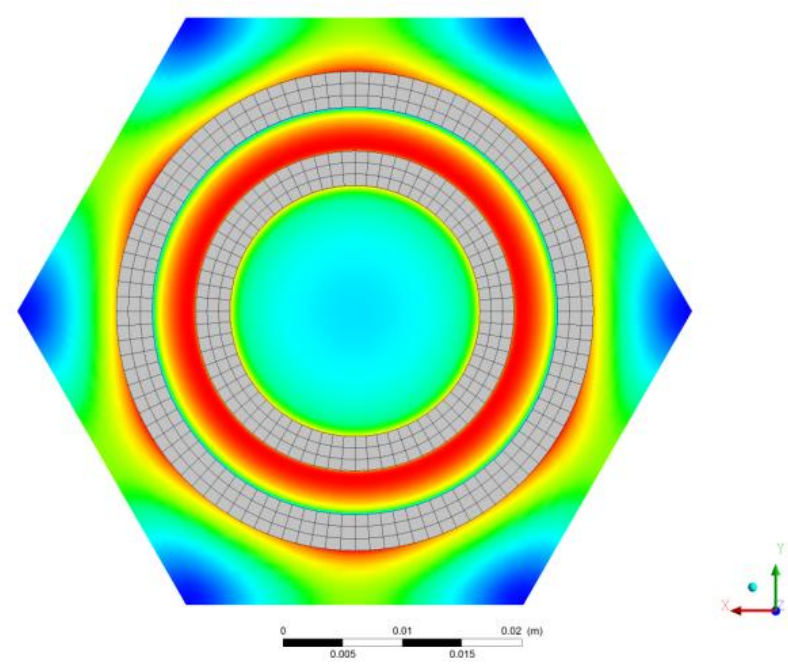

Fig. 5. Temperature distribution in a section of the bayonet pipe.

Fig. 6 shows an example of temperature behaviour computed with RELAP code on the whole HX. In the example, the lead flow rate is fixed to $5.5 \mathrm{~kg} / \mathrm{s}$ and the air mass flow rate at $0.75 \mathrm{~kg} / \mathrm{s}$.

Table 2 shows the main geometrical and physical parameters of the primary heat exchanger.

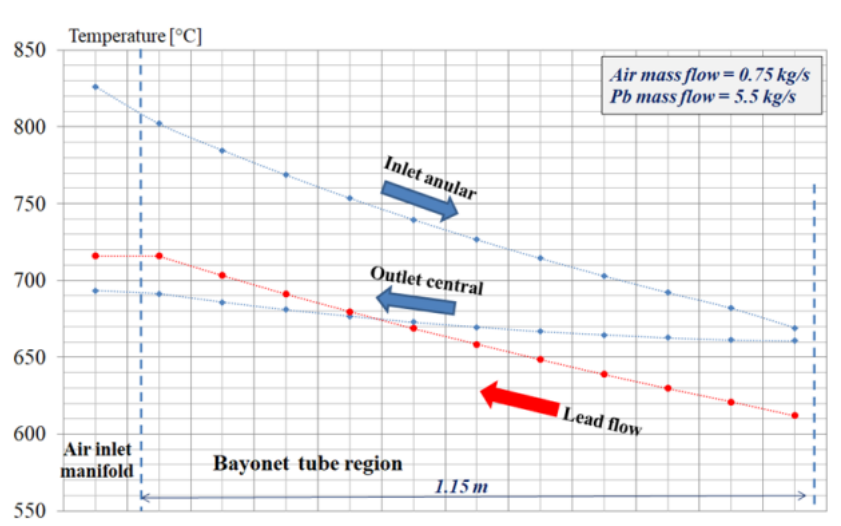

Fig. 6. Temperature profiles in the different zones of HX-0001 with an air mass flow-rate of $0.75 \mathrm{~kg} / \mathrm{s}$.

Table 2. Main geometrical and physical parameters of the primary heat exchanger HX-001.

\begin{tabular}{l|c|c}
\hline \multicolumn{1}{c|}{ Parameter } & Value & Unit \\
\hline Geometries & & \\
\hline Number of tube & 85 & - \\
\hline Inner tube (3/4" S40 commercial) & $3 / 4$ & inch \\
\hline External diameter & 26.67 & $\mathrm{~mm}$ \\
\hline Tube thickness & 2.87 & $\mathrm{~mm}$ \\
\hline External tube & 38 & \\
\hline External diameter & 2 & $\mathrm{~mm}$ \\
\hline Tube thickness & & $\mathrm{mm}$ \\
\hline Bundle & 500 & $\mathrm{~mm}$ \\
\hline Footprint & 49 & $\mathrm{~mm}$ \\
\hline Bundle pitch & 1150 & $\mathrm{~mm}$ \\
\hline Active length & Air $\mathbf{( 0 . 8 5 0}$ bar) & \\
\hline Working fluid (tube side) & 850 & ${ }^{\circ} \mathrm{C}$ \\
\hline $\mathrm{T}_{\text {inlet }}$ & 0.75 & $\mathrm{~kg} / \mathrm{s}$ \\
\hline Total mass flow & Lead & \\
\hline Working fluid (shell side) & 600 & \\
\hline $\mathrm{T}_{\text {inlet }}$ & $5-7$ & $\mathrm{~kg} / \mathrm{s}$ \\
\hline Total mass flow (range estimated) & $\mathbf{1 0 0}$ & $\mathbf{k W}$ \\
\hline Power exchanged & 750 & ${ }^{\circ} \mathrm{C}$ \\
\hline $\mathrm{T}_{\text {outlet }}$ (Pb) & 700 & ${ }^{\circ} \mathrm{C}$ \\
\hline $\mathrm{T}_{\text {outlet }}$ (Air) & &
\end{tabular}

HX1 diagnostics, instrumentations and control are:

- Thermocouples in lead and in air;

- Venturi flow meters in lead;

- Air flow meter in air;

- Pressure transmitters in air and lead.

After interaction with CSP group at ENEA it was clear that to fully demonstrate the storage with thermocline (thermal stratification in the pool), an optimal loading and unloading phase would imply fixed $\Delta \mathrm{T}$ $\left(750^{\circ} \mathrm{C}-600^{\circ} \mathrm{C}\right)$ with fixed lead mass flow rate (design flow rate). This is virtually impossible with natural circulation, in which pressure head varies during the loading, but calculations show that the flow rate does not vary strongly. A correct average lead mass flow rate is obtained for SOLEAD by proper orifice design in the riser for the primary flow path and in the collector for the secondary HX flow path and is around $4.5 \mathrm{~kg} / \mathrm{s}$ for the primary $\mathrm{HX}$ and around $5.5 \mathrm{~kg} / \mathrm{s}$ for the secondary HX. 


\section{Advanced Materials Letters www. vbripress.com/aml}

Moreover, the conceptual air collector design have been fixed, two internal 6 in flanged connections will be used.

In collaboration with CALEF and SANDVIK, an analysis of the best material for each part of the HX-0001 was performed.

Since the primary heat exchanger ( 85 bayonet tubes) will work with air at $0.085 \mathrm{MPa}$ and a max air temperature in the range of $800-850^{\circ} \mathrm{C}$, the main criteria kept in consideration were:

- Steel with common application up to $800-850^{\circ} \mathrm{C}$;

- Good resistance at corrosion in lead $\left(750-800^{\circ} \mathrm{C}\right)$;

- Embrittlement temperature range far from the working one;

- Technological maturity of welding/machinability processes;

- Already approved for use under pressure;

- Availability of experimental results of tests performed in lead at high temperature;

- Avoid welds between different materials.

Table 3 shows the main material choices made for the primary heat exchanger HX-001.

Table 3. Material choice for the primary heat exchanger.

\begin{tabular}{c|c}
\hline Parts of HX1 & Material \\
\hline External tube of bayonet & Kanthal \\
\hline Shell of HX-0001 & Kanthal \\
\hline Riser & Kanthal \\
\hline First bundle plate & Kanthal \\
\hline Inner tubes of bayonet & Sanicro 31HT/ Alloy800 \\
\hline Second bundle plate & Sanicro 31HT/ Alloy800
\end{tabular}

\section{Secondary heat exchanger}

The secondary heat exchanger is used during the thermal discharge phase to transfer heat from the liquid lead to the air in the secondary circuit; therefore, it acst as heat sink in the upper part of the main vessel and triggers the natural circulation in the lead pool.

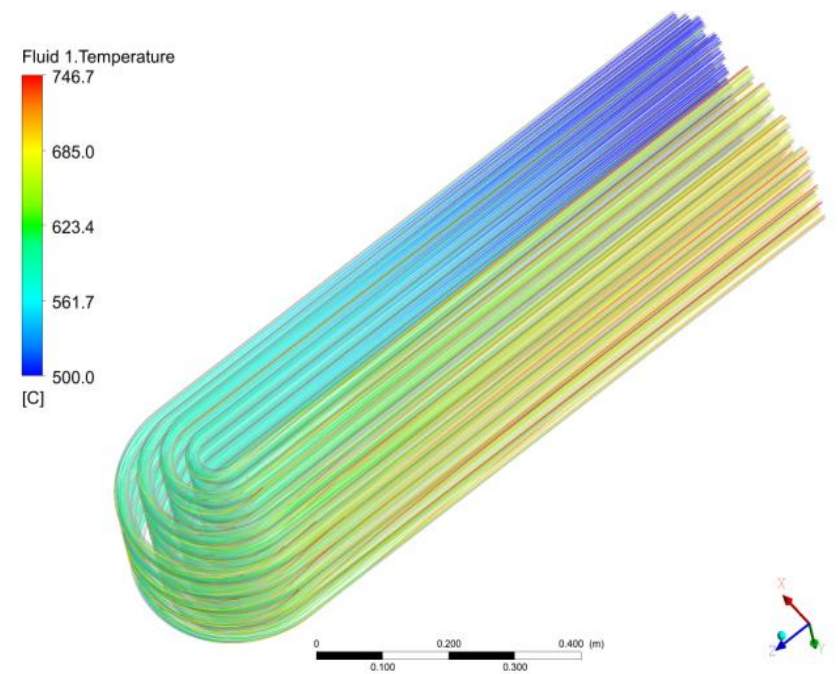

Fig. 7. Temperature distribution in the pipes of the secondary heat exchanger.
The secondary heat exchanger is a $30 \mathrm{U}$-shaped tubes, with air on the tube side. The process fluids are hot lead (shell side) and pressurized air (tube side). The design of the heat exchanger was carried out by extensive use of Computational Fluid Dynamics. The number of tubes and the layout was designed in order to have an exchanged power around $120 \mathrm{~kW}$. Fig. 7 shows the temperature distribution in the secondary heat exchanger by the CFD model.

A collector drives the cold lead in the bottom part of the pool, while the hot lead enters the HX in the top part through proper holes.

In the following Table 4 the main features of the geometrical and functional parameters of the final conceptual design are briefly shown.

Table 4. Main geometrical and functional parameters of the secondary heat exchanger.

\begin{tabular}{l|c|c}
\hline \multicolumn{1}{c|}{ Parameter } & Value & Unit \\
\hline Geometries & & \\
\hline Number of tube (3/4" S40 commercial) & 30 & - \\
\hline External diameter & 26.67 & $\mathrm{~mm}$ \\
\hline Tube thickness & 2.87 & $\mathrm{~mm}$ \\
\hline Bundle & 380 & $\mathrm{~mm}$ \\
\hline Footprint & $\begin{array}{c}37 \text { (a part from the } \\
\text { two central lines } \\
\text { where is } 40)\end{array}$ & $\mathrm{mm}$ \\
\hline Bundle pitch & 1.5 & - \\
\hline Pitch to diameter ratio & 1000 & $\mathrm{~mm}$ \\
\hline Active length & Air (10 bar) & \\
\hline Working fluid (tube side) & 500 & ${ }^{\circ} \mathrm{C}$ \\
\hline $\mathrm{T}_{\text {inlet }}$ & 1 & $\mathrm{~kg} / \mathrm{s}$ \\
\hline Total mass flow & Lead & \\
\hline Working fluid (shell side) & 750 & ${ }^{\circ} \mathrm{C}$ \\
\hline $\mathrm{T}_{\text {inlet }}$ & 5.5 & $\mathrm{~kg} / \mathrm{s}$ \\
\hline Total mass flow (estimated) & $\mathbf{1 2 2}$ & $\mathbf{k W}$ \\
\hline Power exchanged & 600 & ${ }^{\circ} \mathrm{C}$ \\
\hline $\mathrm{T}_{\text {outlet }}$ (Pb) around & 613 & ${ }^{\circ} \mathrm{C}$ \\
\hline $\mathrm{T}_{\text {outlet }}$ (Air) around &
\end{tabular}

In collaboration with CALEF and SANDVIK, an analysis of the best material for each part of the HX-0002 was performed.

Since the secondary heat exchanger (shell/tubes) will work with air at $1.0 \mathrm{MPa}$ and a maximum air/lead temperature of $750{ }^{\circ} \mathrm{C}$, the main criteria kept in consideration were:

- Steel with common application up to $750{ }^{\circ} \mathrm{C}$;

- Good resistance to corrosion in lead;

- Embrittlement temperature range far from the working one;

- Technological maturity of welding/machinability processes;

- Already approved for use under pressure;

- Availability of experimental results of tests performed in lead at high temperature;

- Avoid welds between different materials.

The material choices for the secondary heat exchanger are summarized in Table 5. 


\section{Advanced Materials Letters \\ www. vbripress.com/aml}

Table 5. Material for the different parts of the secondary heat exchanger HX-002.

\begin{tabular}{l|l}
\hline \multicolumn{1}{c|}{ Parts of HX-0002 } & \multicolumn{1}{c}{ Material } \\
\hline Bundle tubes & $\begin{array}{l}\text { Composite material (Sanicro 31 } \\
\text { HT/Alloy 800 + Loafer) }\end{array}$ \\
\hline Shell of HX-0002 & Kanthal \\
\hline Septum & Kanthal \\
\hline Bundle plate & Sanicro 31 HT/Alloy 800 \\
\hline Flanged connection of HX-0002 & Sanicro 31 HT/Alloy 800 \\
\hline
\end{tabular}

\section{Conclusion}

The conceptual design of the TES demonstrator SOLEAD for CSP application is reported in the paper. The inspiration for the general layout of the DEMO comes from the pool facilities with Heavy Liquid Metal already built and operated at the ENEA Brasimone R.C. (e.g. CIRCE facility). A massive technological transfer from Nuclear GEN-IV to CSP was carried out. The design of the Demonstrator made large use of Computational Fluid Dynamics tools and System Thermal-hydraulic tools commonly used in the nuclear field like RELAP.

The basic dimensions of the main vessel are an inner diameter of $1160 \mathrm{~mm}$, and a height of $3.6 \mathrm{~m}$. Inside this component, two heat exchangers are placed, namely the primary heat exchanger and the secondary heat exchanger, devoted to the thermal charging and discharging of the system. The design of proper collectors allowed the establishment of a temperature stratification in the pool in the range $600^{\circ} \mathrm{C}-750^{\circ} \mathrm{C}$. Most of the effort was devoted to the design of the primary and secondary HX by a large use of CFD tools. The final solution was a bayonet type for the primary depressurized air/Lead HX, and a U-tube pipe for the secondary lead/air HX. The choice of the materials was also a difficult issue because lead at $750^{\circ} \mathrm{C}$ is corrosive. Therefore a large use of $\mathrm{FeCrAl}$ materials as overlay welding, coatings or full material, is made. For example for the external pipes of the primary heat exchanger a kanthal tube is chosen.

The location of the heat exchangers allows the development of natural circulation in the loop. The primary HX is located in the lower part and a riser drives the hot fluid into the upper part of the vessel for the thermal stratification. The secondary heat exchanger is in the top part and a collector drives the cold fluid in the bottom part.

Both charging and discharging phases are driven by natural circulation and the correct average flow rate in the $\mathrm{HX}$ is regulated by a orifice.

\section{Acknowledgements}

This work was perfomed within the NEXTOWER project, funded by the European Commission H2020 research and innovation programme under grant agreement 721045 .

\section{Keywords}

CSP, heavy liquid metal, innovative HX design.

\section{References}

1. Mehos, M.; Turchi, C.; Vidal, J.; Wagner, M.; Ma, Z.; Ho, C.; Kolb, W.; Andraka, C.; Kruizenga, A.; "Concentrating Solar Power Gen3 Demonstration Roadmap", Technical Report NREL/TP5500-67464, january 2017.

2. Fernandez, A.G.; Gomez-Vidal, J.; Orò, E.; Kruizenga, A.; Solé, A.; Cabeza, L.F.; "Mainstreaming Commercial CSP Systems: A Technological Review”, Renewable Energy, 2019, 140, 152.

3. K. Henneke et al. (2008), "The Solar Power Tower Julich-A Solar Thermal Power Plant for Test and Demostration of Air Receiver Technology", in D.Y. Goswami, Y. Zhao (Eds) Proceeding of ISES World Congress 2007, (Vol.I-Vol.V) Ed. Springer, Berlin, Heidelberg.

4. Bassini, S.; Antonelli, A.; Di Piazza, I.; Tarantino, M.; J. Nuc. Mat., 2017, 486, 197.

5. Martelli, D.; Tarantino, M.; Di Piazza, I.; "Experimental Activity for the Investigation of Mixing and Thermal Stratification Phenomena in the Circe Pool Facility" Proceedings of the 2016 , 24th International Conference on Nuclear Engineering, ICONE2460920, June 26-30, 2016, Charlotte, North Carolina.

6. Di Piazza, I.; Angelucci, M.; Marinari, R.; Tarantino, M.; Forgione, N.; Nucl. Eng. Des., 2016, 300, 256.

7. Lorusso, P.; Bassini, S.; Del Nevo, A.; Di Piazza, I.; Giannetti, F.; Tarantino, M.; Utili, M.; Prog. Nuc. Energy, 2018, 105, 318.

8. Martelli, D.; Bassini, S.; Tarantino, M.; Di Piazza, I.; "CIRCE-ICE experimental activities in support of LMFR Design" Proceedings IAEA FR17.

9. Tarantino, M.; Martelli, D.; Barone, G.; Di Piazza, I.; Forgione, N.; Journal of Nuclear Engineering and Design, 2015, 286, 261.

10. Handbook on Lead-bismuth Eutectic Alloy and Lead properties, Materials Compatibility, Thermal-Hydraulics and Technologies, OCED-NEA Handbook, Nuclear Science, 2015.

11. Roloefs F. Ed., Thermal Hydraulic Aspects of Liquid Metal Cooled Nuclear Reactor, Elsevier, 2018

12. Bassini, S.; Antonelli, A.; Di Piazza, I.; Tarantino, M.; Prog. Nuc. Energy, PNUCENE- 2018, 105, 137.

13. Valdiserri, M.; Main Process for the Logical Control of SOLEAD facility, ENEA Report LM-I-R-260, 10/10/2017. 